The Australasian Accounting Business \& Finance Journal, December, 2008.

Baird, Perera \& Meng: Managers' Propensity to Take Risk in Project Selection Decisions.

Vol. 2, No.4.

\title{
MANAGERS' PROPENSITY TO TAKE RISK IN PROJECT SELECTION DECISIONS: THE EFFECT OF PAYOFF MAGNITUDE
}

\author{
Kevin Baird \\ Macquarie University \\ Sujatha Perera \\ Macquarie University \\ Ting Ting Meng \\ PricewaterhouseCoopers
}

\begin{abstract}
This paper examines the factors that influence managers' propensity to take risk in project selection decision contexts with a special focus on payoff magnitude as an influencing factor. This study utilises an experimental research design to examine this relationship in a project selection context. The results reveal that there is an inverse relationship between payoff magnitude and the participants' propensity to take risk with individuals becoming more risk averse as the level of payoff magnitude increases. The study also provides an insight into the key factors considered by risk averse and risk taking managers when making project selection decisions.
\end{abstract}

Key words: Payoff magnitude; Propensity to take risk; Project selection.

\section{Introduction}

As an essential part of business development and expansion, managers frequently engage in capital budgeting decisions in which they evaluate and select among investment projects that differ in timing, magnitude, and unpredictability of cash flows. While many studies have examined managers' project evaluation decisions (Booth and Schulz 2004; Rutledge and Karim 1999; Harrison et al. 1999) there has been only limited research on the effect of payoff magnitude on the propensity of managers to take risk when choosing between alternatives, particularly in project selection contexts.

The current study is primarily motivated by Bonner and Sprinkle (2002: 335) who posed the question whether increasing the level of rewards would necessarily induce risk taking behaviour. They note that individuals are locally risk-neutral or engender more risk-averse behaviour. While a number of previous studies (eg., Binswanger 1980; Holt and Laury 2002; Kachelmeier and Shehata 1992) have demonstrated that individuals become more risk averse as payoff magnitude increases, those studies have used lottery choice data with individuals making decisions which affected their personal returns.

The purpose of this study is to examine the effect that monetary incentives (payoff magnitude) have on the propensity to take risk in a project selection context. Specifically, the study examines whether increasing the payoff magnitude affects the propensity of individuals to take risk when choosing between two alternative projects which have varying returns and risks 
The Australasian Accounting Business \& Finance Journal, December, 2008.

Baird, Perera \& Meng: Managers' Propensity to Take Risk in Project Selection Decisions.

Vol. 2, No.4.

associated with them. The study also provides insights into the extent to which specific factors are considered when making project selection decisions.

The remainder of the paper is structured as follows. The next three sections discuss the relevant literature on project selection, monetary incentives, and the effect of payoff magnitude on project selection respectively. These discussions lead to the formulation of a hypothesis linking payoff magnitude and the propensity to take risk. A number of other factors that could influence managers' project selection decisions are then discussed. This discussion leads to the formulation of a further two hypotheses. The experimental design and the measurement of variables are then described. The final two sections provide the results of the experiment followed by a discussion of the findings of the study.

\section{Project selection}

Agency theory suggests that managers are typically risk averse when making project selection decisions. There are two main reasons for this. First, agents (managers) are naturally motivated to over-consume leisure, attractive working conditions and company perquisites, and hence will not invest sufficient time and effort to increase shareholder value. Also, given the opportunity, managers are willing to ignore the pledges made during contract negotiations about the level of effort, skill and knowledge they will provide the firm (Baiman 1990). Consequently, in a project selection context, if managers perceive a project to be high risk, even if there is a possibility for them to gain a high reward, they may opt for a low risk project due to the uncertainty of the magnitude of cash flows associated with the high risk project, and the personal costs associated with giving their effort, skill, and knowledge to increase shareholder value. When personal costs are equal for two projects with different risk levels, managers are still likely to select the low risk project due to a greater likelihood of achieving some financial outcomes. Managers are able to engage in such sub-optimal behaviour due to the limited ability of principals' (owners/shareholders) and other managers to observe and monitor agents' (managers') behaviours without incurring extra costs (Baiman 1990; Eisenhardt 1985; Harell and Harrison 1994; Harrison and Harell 1993).

Second, given that managers bear a company's overall risk which they cannot diversify, they are likely to select less risky projects in order to guarantee their position in the firm (Jeitschko and Jeung 2005; Lee 2002; Amihud and Lev 1981). Specifically, managers will choose more certain, yet lower return projects, as they believe that stable earnings will be viewed positively by the shareholders (principals), and hence reduce the likelihood that they will be dismissed (Gamble 2000). Similarly, managers may also be reluctant to select risky projects due to the potential threat to their employment if the company were to become bankrupt following the failure of high risk projects. Consequently, in order to avoid the threat of losing employment, managers are likely to behave in a risk-averse fashion when selecting projects as the potential costs involved with taking risk could exceed the potential benefits (Lee 2002).

While agency theory suggests that managers are inherently risk averse, prospect theory (Kahneman and Tversky 1979) postulates that decision makers will tend to be risk averse when deciding between alternatives that would yield potential gains, and risk seeking when faced with alternatives that are likely to result in losses in an attempt to minimise the loss (Moreno et al. 2002; Cohen and Trompeter 1998; Christian and Gupta 1994; Sullivan and Kida 1995; Lipe 1993). Given that employees often share in a company's success but are rarely penalised if the 
The Australasian Accounting Business \& Finance Journal, December, 2008.

Baird, Perera \& Meng: Managers' Propensity to Take Risk in Project Selection Decisions.

Vol. 2, No.4.

Page 55.

selected project fails (Hannan 2005), the selection of investment projects typically presents a gain context. Accordingly prospect theory maintains that managers are likely to exhibit risk averse behaviour in project selection decision contexts.

\section{Monetary incentives}

There is considerable literature that examines the role of both monetary and non-monetary incentives in motivating effort and improving managers' performance (Atkinson et al. 2003; Horngren et al. 2005; Zimmerman 2000). However, most of the literature in this area has focused on the motivational effect of incentives on task performance (Bonner and Sprinkle 2002), and there has been only limited research examining how incentives may influence managers' risktaking behaviour.

Monetary incentives typically include wages, bonuses, stock options and perquisites, and are seen as primary methods of compensation for motivating individuals' effort and hence improving their performance. Expectancy theory suggests that individuals act to maximise expected satisfaction with outcomes (Vroom 1964). It posits that an individual's motivation in a particular situation is a function of three factors, namely, expectancy, instrumentality and valence. Accordingly, an individual's motivation is influenced by the expectancy that the effort will lead to desired performance (i.e., expectancy), the perception that desired performance will lead to outcomes (eg. intrinsic and extrinsic outcomes) (i.e., instrumentality) and the attractiveness of the outcomes (i.e., valence). Expectancy theory, hence suggests monetary incentives as a factor that has the potential to motivate desired behaviour, such as risk taking behaviour.

The current study will examine the role of monetary incentives in inducing risk taking behaviour in a project selection decision context. More specifically, the study examines a project selection decision situation where managers have to decide whether to choose the less risky (safer) project that has a higher expectancy of achieving a desired performance and a lower reward, or to choose the riskier project that has a lower expectancy of achieving the desired performance but a higher reward.

\section{The effect of payoff magnitude on project selection}

A few studies have examined the relationship between payoff magnitude and the propensity to take risk (Holt and Laury 2002; Kachelmeier and Shehata 1992; Binswanger 1980). Binswanger (1980), for instance, used an experimental gambling approach with real payoffs and found that the level of risk aversion increased as the payoff magnitude increased. Similarly, using lottery choice data, Kachelmeier and Shehata (1992) examined the relationship between risk taking behaviour and payoff magnitude and found that subjects were more risk averse when monetary prizes were larger. Kachelmeier and Shehata (1992) used certainty equivalents for individual lotteries which were considered separately by respondents. Both of these studies offered real monetary outcomes and were conducted using low wealth respondents who were able to earn their monthly income as part of the experiment. It is possible therefore that their responses were influenced by the respondents need for personal wealth.

Holt and Laury (2002) also assess the effect of incentives on risk aversion and found that there was an increase in risk aversion as payoffs increased. Holt and Laury (2002) conducted 
The Australasian Accounting Business \& Finance Journal, December, 2008.

Baird, Perera \& Meng: Managers' Propensity to Take Risk in Project Selection Decisions.

Vol. 2, No.4.

Page 56.

their experiment with both hypothetical and real payoffs and found that while subjects are much more risk averse with high real payoff levels there was no change as hypothetical payoffs increased.

Bonner and Sprinkle (2002) indicate that the effect of higher payoff magnitudes on risk taking behaviour could be either way. Specifically, they indicate that a higher pay off could motivate a higher propensity to take risk due to the potential for receiving greater rewards (via bonuses linked to the project performance) or alternatively, it may lead to managers behaving in an even more risk averse manner due to the increased pressure associated with riskier projects.

Hence, it can be argued that in project selection contexts, payoff magnitude could influence managers' propensity to take risk. This study therefore empirically tests the following hypothesis stated in its null form.

Hypothesis 1: $\quad$ There is no causal link between payoff magnitude and the propensity to take risk when making project selection decisions.

\section{Factors that influence the propensity to take risk}

The second part of this study was aimed towards providing an insight into the specific factors that influence project selection decisions. Traditional decision making theory maintains that the magnitude and probability of achieving specific outcomes influences risk taking behaviour (Baucells and Rata 2006). Accordingly, six factors focusing on the magnitude of potential returns available and the probability of achieving certain outcomes were chosen and subsequently evaluated for their influence on the project selection decision. Specifically, participants in the experiment were asked to evaluate the extent to which they considered the probability that each project will generate a loss, the probability that no bonus will be received, the probability that each project will generate a positive return, the distribution of positive returns for each project, the level of the maximum bonus available, and the level of weighted average expected bonus. A comparison of the extent to which each of these factors were considered by risk takers and risk averse respondents when making their project selection decision was subsequently undertaken.

Risk averse managers 'prefer relatively low risk and are willing to sacrifice some expected return in order to reduce the variation in possible outcomes' (March and Shapira 1987: 1406). They prefer to adopt the safer option in an attempt to minimise the negative impact of their decisions, and are prepared to forgo potential higher returns by choosing less risky projects which enable them to maintain a stable pattern of returns and be viewed favourably by shareholders (Gamble 2000), thereby minimising the likelihood of their dismissal.

Given risk averse managers wish to minimise the risk associated with projects it is expected that they will be more likely to focus on the negative aspects associated with projects in making project selection decisions. Specifically, they are likely to pay particular attention to factors such as the probability that each project will generate a loss, and the probability that no bonus will be received. Slovic (1967) found that the degree of risk taking decreased as the probability of a loss increased. The probability of a loss and the probability that no bonus will be received will be higher for riskier projects and hence, risk averse managers will choose the less 
The Australasian Accounting Business \& Finance Journal, December, 2008.

Baird, Perera \& Meng: Managers' Propensity to Take Risk in Project Selection Decisions.

Vol. 2, No.4.

risky project. Accordingly, such factors are expected to be considered to a greater extent by risk averse managers as compared to risk seeking managers when making their decision. This discussion results in hypothesis two below.

Hypothesis 2: Those managers who are risk averse will consider: - (i) the probability that each project generates a loss and (ii) the probability that no bonus will be received to a greater extent when making their decision than those managers who are risk takers.

Alternatively, risk seeking or risk taking managers prefer more risk and are prepared to select riskier projects in an attempt to achieve higher returns. Risk seeking managers must be enticed to accept greater risk through the "relative attractiveness of the risky choice" (Baucells and Rata 2006: 170). Given risk takers are content to adopt greater risk, they are expected to place greater emphasis on the positive aspects associated with projects. Specifically, it is anticipated that risk seeking managers will consider the probability that each project generates a positive return, the distribution of positive returns, the level of the maximum bonus available, and the level of weighted average expected bonus to a greater extent than risk averse managers when making their decision, resulting in hypothesis three below.

Hypothesis 3: Those managers who are risk takers will consider the (i) the probability that each project generates a positive return (ii) the distribution of positive returns for each project (iii) the level of the maximum bonus available and (iv) the level of weighted average expected bonus to a greater extent when making their decision than those managers who are risk averse.

\section{METHOD}

\section{Experiment design}

An experiment was conducted using a between-subjects design. The experiment was designed to simulate an investment decision making environment in which participants (undergraduate students) were asked to assume the role of a general manager responsible for making a project selection decision. Adopting a hypothetical setting has enabled consistency in respect to the characteristics of respondents given the potential of numerous characteristics (such as industry, experience, and personal wealth) to affect the project selections decisions of real managers.

Participants were required to select between two projects which differed in respect to their potential returns and the associated level of risk. Each participant was given a return distribution table (see Appendix A) which outlined the probability of achieving six different levels of return outcomes for each of the two alternative projects (projects A and B). The magnitude of the returns (payoff magnitude) differed across the three alternative scenarios developed for this study. Each participant was given only one of the three scenarios. This allowed us to determine the effect of the different levels of payoff magnitude on the participant's propensity to take risk, as measured by the proportion of participants choosing the more risky project in each decision scenario. 
The Australasian Accounting Business \& Finance Journal, December, 2008.

Baird, Perera \& Meng: Managers' Propensity to Take Risk in Project Selection Decisions.

Vol. 2, No.4.

Page 58.

In each scenario, Project A was designed to be riskier than project B in two ways. Firstly, project $A$ had a wider spread of expected return outcomes than project B and therefore, project A could generate both higher possible gains and higher possible losses. Secondly, project A had a higher possibility of generating a loss for the company, and correspondingly a higher possibility that participants would not receive any bonus. ${ }^{1}$ In each scenario, we confirmed that project A was indeed riskier than project B by calculating the level of risk associated with the two projects using the following financial formula.

$$
R i s k=\sqrt{\sum_{i=1}^{n} \operatorname{prob}[\text { return }-E(\text { return })]}(\text { Haugen 2001: 72) }
$$

To eliminate the possible confounding effects if participants were to make their choice based on the weighted average expected return (WAER) rather than the amount of bonus rewards that were likely to be received, the WAERs were designed to be equal for the two projects. In addition, the WAER was clearly stated along with the two projects' respective risk-return information. Similarly, given task complexity is a significant factor that may moderate the effectiveness of incentive rewards in their own right (Simnett 1996; Bonner and Sprinkle 2002) participants were informed that both projects involved the same degree of difficulty.

\section{Sample}

The experiment was administered to 424 second-year undergraduate university students enrolled in an introductory management accounting unit at a major Australian university. The students volunteered to participate in the study and completed the project selection task during classes. The majority of the students had previously studied or were currently studying a relevant finance subject so they were deemed to have attained the level of knowledge required in order to complete the experiment.

The students also completed a post-experiment questionnaire (see Appendix B) designed to ensure that they understood the two main constructs in the experiment, namely the nature of risk and payoff magnitude. Specifically, the students were required to identify which of the two projects had the highest risk, and which of the two projects generated a higher bonus. The responses made by students who failed to correctly identify the project with the highest risk or the project which generated the highest bonus were omitted as their failure to understand the basic design of the experiment meant that their choice of projects was based on a different criterion to that intended. Consequently, 167 of the 424 responses received were removed with the data analysis conducted on the remaining 257 responses $^{2}$.

The post-experiment questionnaire was also designed to evaluate the specific factors that affected participants' project selection decisions. Specifically, participants were required to indicate the extent to which the six factors identified in hypotheses 2 and 3 were considered in

\footnotetext{
${ }^{1}$ The probability of no bonus to participants consists of the sum of the probabilities of generating a loss and zero return for the company.

${ }^{2}$ While the presented results reflect the reduced sample, statistical tests were also performed on the entire sample with similar results found.
} 
The Australasian Accounting Business \& Finance Journal, December, 2008.

Baird, Perera \& Meng: Managers' Propensity to Take Risk in Project Selection Decisions.

Vol. 2, No.4.

Page 59.

choosing between the two projects, using a seven-point Likert scale with anchors of 1 'Not at all' and 7 'To a great extent'.

\section{Variable measurement}

Propensity to take risk

Risk is often considered in the fields of finance, mathematics, psychology and decision sciences with many different meanings across the different disciplines (Jia et al. 1999; Jia 1995). Previous finance and accounting literature which studied the association between executive compensation and risk used the volatility of returns as the measure of risk (Garen 1994; Aggarwal and Samwick 1999). Similarly, this study measures the risk of a project based on the dispersion of its expected returns, and the likelihood of expected losses.

In each scenario project $A$ had a wider spread of expected return outcomes and a greater likelihood of generating a loss than project $\mathrm{B}$ and hence, project $\mathrm{A}$ was considered to be the riskier project. For instance, in scenario 1 (see Appendix A) the possible return outcomes of project A vary from $-8 \%$ to $15 \%$ (a spread of $23 \%$ ), compared to that of project $\mathrm{B}$, which vary from $-4 \%$ to $10 \%$ (a spread of $14 \%$ ). In addition, project $A$ had a 0.30 probability of generating a loss while project $\mathrm{B}$ only had a 0.10 probability of generating a loss. The propensity to take risk in the current study is operationalised as the proportion of respondents choosing the riskier project $A$ in each of the decision scenarios. The study will observe if this proportion varies as the payoff magnitude changes across the three scenarios.

\section{Payoff magnitude}

Payoff magnitude was operationalised through the manipulation of the maximum bonus level (return outcome) that participants could receive if the riskier project was successful and the weighted average expected return. Specifically, the maximum bonus rate participants could receive if selecting project $\mathrm{A}$ was $15 \%$ in scenario $1,25 \%$ in scenario 2 , and $35 \%$ in scenario 3 . At the same time, the weighted average expected bonus increased from $4.2 \%$ in scenario 1 to $6.6 \%$ and $8.7 \%$ in scenarios 2 and 3 respectively.

Participants were informed that their bonus at the end of the year would be equal to their annual salary multiplied by the rate of return generated by the chosen project. They were also informed that they would receive their normal pay and no penalty would be imposed if the project generated a loss. Hence, in each scenario participants would receive higher bonuses if they chose the riskier project and subsequently achieved the maximum return outcome.

\section{RESULTS}

Table 1 presents the results of the Pearson Chi-square analysis conducted to compare the proportions of participants who selected projects A and B under each of the three payoff magnitude scenarios $(15 \%, 25 \%, \& 35 \%)$. The observed Chi-square result (10.512) is statistically significant at the 5\% significance level (2-sided) indicating that the proportion of participants choosing each project across the three scenarios can not be attributed to a chance distribution. When the payoff magnitude (as measured by the level of maximum bonus available for project A) was $15 \%, 70.13 \%$ of the participants selected project $A$; in the $25 \%$ bonus scenario, $58.97 \%$ 
The Australasian Accounting Business \& Finance Journal, December, 2008.

Baird, Perera \& Meng: Managers' Propensity to Take Risk in Project Selection Decisions.

Vol. 2, No.4.

Page 60.

of the participants selected project A; while in the $35 \%$ bonus scenario, only $46.08 \%$ of the participants selected project A. Such results reveal a clear downward (upward) trend in the proportion of participants selecting the higher-risk project A (lower-risk project B) as the payoff magnitude moved from the lower bonus scenario to the higher bonus scenario. These results allow us to reject the null hypothesis (H1) and conclude that as the payoff magnitude increases, there is a decreasing propensity to take risk when selecting projects.

Table 1

Project selection rates for the three payoff levels

\begin{tabular}{|l|l|l|l|}
\hline \multirow{2}{*}{} & \multicolumn{2}{|l|}{ Payoff Magnitude } \\
\cline { 2 - 4 } & $15 \%$ Scenario $^{\dagger}$ & $25 \%$ Scenario $^{\dagger}$ & $35 \%$ Scenario $^{\dagger}$ \\
\hline Project A & $54(70.13 \%)$ & $46(58.97 \%)$ & $47(46.08 \%)$ \\
\hline Project B & $23(29.87 \%)$ & $32(41.03 \%)$ & $55(53.92 \%)$ \\
\hline Chi-sq value & 10.512 & & \\
\hline Df & 2 & & \\
\hline Sig (2-sided) & $\mathbf{0 . 0 1} * *$ & & \\
\hline
\end{tabular}

$\mathrm{N}=257\left(\mathrm{~N}_{15 \%}=77, \mathrm{~N}_{25 \%}=78, \mathrm{~N}_{35 \%}=102\right)$

** Significant at 5\% level (2-tailed)

$\dagger$ Measured by maximum bonus level available

Table 2 provides the mean scores in respect to the extent to which each of the identified factors were considered by respondents when making project selection decisions. The analysis reveals that the top two factors considered by those participants who selected the less risky project $\mathrm{B}$ (110 out of 257$)$ were the probability that each project generates a positive return $\left(\mathrm{M}_{\mathrm{B}}=\right.$ 4.94), and the distribution of positive returns for each project $\left(M_{B}=4.76\right)$. While Hypothesis 2 maintained that the probability that each project generates a loss would be considered by risk averse managers this factor was only ranked as the third most important factor $\left(\mathrm{M}_{\mathrm{B}}=4.58\right)$. In addition, the other factor mentioned in Hypothesis 2, the probability of no bonus being received, was ranked as the least considered factor $\left(\mathrm{M}_{\mathrm{B}}=3.77\right)$. The top four factors considered to the greatest extent by participants who selected the more risky project A (147 out of 257) were the level of the maximum bonus available $\left(\mathrm{M}_{\mathrm{A}}=5.22\right)$, the probability that each project generates a positive return $\left(\mathrm{M}_{\mathrm{A}}=5.13\right)$, the distribution of positive returns for each project $\left(\mathrm{M}_{\mathrm{A}}=5.09\right)$, and the weighted average expected bonus $\left(\mathrm{M}_{\mathrm{A}}=4.60\right)$. These findings are consistent with Hypothesis 3 which maintains that that these factors would be considered to a greater extent by risk takers. 
The Australasian Accounting Business \& Finance Journal, December, 2008.

Baird, Perera \& Meng: Managers' Propensity to Take Risk in Project Selection Decisions.

Vol. 2, No.4.

Page 61.

Table 2

Comparison of the importance of various explanatory factors when selecting between projects

\begin{tabular}{|c|c|c|c|c|c|}
\hline & \multicolumn{5}{|c|}{ t-test for Equality of Means } \\
\hline & $\begin{array}{l}\text { Project A mean } \\
\text { (Std. dev) }\end{array}$ & $\begin{array}{l}\text { Project B mean } \\
\text { (Std. dev) }\end{array}$ & $\begin{array}{l}\text { Mean } \\
\text { Difference }\end{array}$ & $\mathrm{t}$ value & $\begin{array}{l}\text { Sig. } \\
\text { (2-tailed) }\end{array}$ \\
\hline $\begin{array}{l}\text { Probability of } \\
\text { Loss }\end{array}$ & $\begin{array}{l}4.01 \\
(1.74)\end{array}$ & $\begin{array}{l}4.58 \\
(1.68)\end{array}$ & -0.57 & -2.66 & $0.01 * *$ \\
\hline $\begin{array}{l}\text { Probability of No } \\
\text { Bonus }\end{array}$ & $\begin{array}{l}3.77 \\
(1.82)\end{array}$ & $\begin{array}{l}3.77 \\
(1.68)\end{array}$ & -0.00 & -0.02 & 0.99 \\
\hline $\begin{array}{l}\text { Probability of } \\
\text { Positive Returns }\end{array}$ & $\begin{array}{l}5.13 \\
(1.73)\end{array}$ & $\begin{array}{l}4.94 \\
(1.44)\end{array}$ & 0.19 & 0.95 & 0.34 \\
\hline $\begin{array}{l}\text { Distribution of } \\
\text { Positive Returns }\end{array}$ & $\begin{array}{l}\mathbf{5 . 0 9} \\
(1.45)\end{array}$ & $\begin{array}{l}\mathbf{4 . 7 6} \\
(1.36)\end{array}$ & 0.33 & 1.83 & 0.07* \\
\hline $\begin{array}{l}\text { Maximum Bonus } \\
\text { Level }\end{array}$ & $\begin{array}{l}5.22 \\
(1.60)\end{array}$ & $\begin{array}{l}4.13 \\
(1.52)\end{array}$ & 1.09 & 5.56 & $0.00 * *$ \\
\hline $\begin{array}{l}\text { WAEBonus Level } \\
\wedge\end{array}$ & $\begin{array}{l}4.60 \\
(1.59)\end{array}$ & $\begin{array}{l}4.14 \\
(1.53)\end{array}$ & 0.46 & 2.34 & $0.02 * *$ \\
\hline
\end{tabular}

$\mathrm{N}=257\left(\mathrm{~N}_{\mathrm{A}}=147, \mathrm{~N}_{\mathrm{B}}=110\right)$

** Significant at 5\% level (2-tailed)

* Significant at $10 \%$ level (2-tailed)

In order to test hypotheses 2 and 3 a comparison of the mean scores in regard to the extent to which each factor was considered when making the project selection decision was made between participants that selected each of the two projects. The results are also presented in Table 2 and reveal that participants who selected project B (risk averse) considered the probability of generating a loss $(\mathrm{p}=0.01)$ to a greater extent than participants who selected project A (risk takers). This finding provides partial support for hypothesis 2 , with the other hypothesised factor (the probability that no bonus will be received) not considered to a greater extent by risk averse managers when making their decision.

Alternatively, those participants who selected project A (risk takers) considered the maximum bonus available $(p=0.00)$, and the weighted average expected bonus $(p=0.02)$ to a greater extent than participants who selected project B (risk averse). These results provide partial support for hypotheses three with two out of the four hypothesised factors considered to a greater extent by risk takers when making their project selection decision (the probability that each project generates a positive return and the distribution of positive returns for each project were not significantly different).

Binary logistic regression was performed in order to further examine the relationship between payoff magnitude and each of the factors considered in making the project selection decisions (Appendix B) with the participant's project selection decisions. The results of this analysis (see Table 3) confirm that payoff magnitude affects project selection decisions with participants becoming more risk averse as the payoff magnitude increased. In respect to the factors considered in making the project selection, the probability of a loss and the maximum bonus level were the only two factors that had a significant effect. Participants who considered the maximum bonus to a greater extent were more likely to have chosen the more risky project (Project A). Alternatively, participants who considered the probability of a loss to a greater extent 
The Australasian Accounting Business \& Finance Journal, December, 2008.

Baird, Perera \& Meng: Managers' Propensity to Take Risk in Project Selection Decisions.

Vol. 2, No.4.

Page 62.

were more likely to choose Project B. These findings provide further support for hypotheses 2 and 3.

Table 3

Logistic regression results - Impact of factors on project selection

Dependent variable $=$ Project selection

\begin{tabular}{|c|c|c|c|c|}
\hline & All scenarios & $\begin{array}{l}\text { Scenario } 1-\text { Max } \\
\text { bonus of } 15 \% \text { for } \\
\text { Project A }\end{array}$ & $\begin{array}{llr}\text { Scenario } 2 & - & \text { Max } \\
\text { bonus of } 25 \% & \text { for } \\
\text { Project A } & & \\
\end{array}$ & $\begin{array}{l}\text { Scenario } 3-\text { Max } \\
\text { bonus of } 35 \% \text { for } \\
\text { Project A }\end{array}$ \\
\hline Variable & $\begin{array}{ll}\text { Coeff } & \text { Wald } \\
& \text { T-stat }\end{array}$ & $\begin{array}{ll}\text { Coeff } & \text { Wald } \\
& \text { T-stat }^{\dagger}\end{array}$ & $\begin{array}{ll}\text { Coeff } & \text { Wald } \\
& \text { T-stat }\end{array}$ & $\begin{array}{ll}\text { Coeff } & \text { Wald } \\
& \text { T-stat } \\
\end{array}$ \\
\hline Constant & .44 & .01 & 1.26 & $3.95 \quad 8.76^{* *}$ \\
\hline LOSS & .01 & .87 & 2.27 & $4.99 *$ \\
\hline NOBONUS & .84 & .61 & .03 & .58 \\
\hline BONUS & -.09 & -.15 & .57 & 3.24 \\
\hline RETURNS & -.11 & -.09 & -.22 & $\begin{array}{ll}.08 & 0.19 \\
\end{array}$ \\
\hline MAX & -.46 & 3.03 & $6.93 * *$ & $\begin{array}{ll}-.56 & 11.08 * * \\
\end{array}$ \\
\hline WEIGAVE & -.04 & .14 & -.10 & $\begin{array}{ll}-.19 & 1.43 \\
\end{array}$ \\
\hline PAYOFF & .00 & & & \\
\hline $\begin{array}{l}\text { Model Chi- } \\
\text { square }\end{array}$ & $52.69 * *$ & 6.61 & $13.91 * *$ & $30.48 * *$ \\
\hline $\begin{array}{ll}-2 & \log \\
\text { likelihood } & \end{array}$ & 298.24 & 87.29 & 91.70 & 110.29 \\
\hline $\begin{array}{l}\% \text { correct } \\
\text { predictions }\end{array}$ & $72.4 \%$ & $70.1 \%$ & $75.6 \%$ & $75.5 \%$ \\
\hline Nagelkerke $\mathrm{R}^{2}$ & .249 & .117 & .220 & .345 \\
\hline
\end{tabular}

*Significant at $5 \%$ significance level

** Significant at 1\% significance level † Tabachnick and Fidell 2001, p.524

LOSS - the probability that each project generates a loss; NOBONUS - the probability that no bonus will be received; BONUS - the probability that each project generates a positive return (getting bonus); RETURNS - the distribution of positive returns for each project; MAX - the level of the maximum bonus available; WEIGAVE - the level of weighted average expected bonus; PAYOFF - the level of maximum payoff available under the three scenarios.

Binary logistic regression was also performed in order to examine the relationship between the six identified factors and participants' project selection decisions across each of the three decision scenarios. The results of the logistic regression analysis are also presented in Table 3 with three models developed based on the three different levels of payoff magnitude operationalised in scenarios 1-3 of the study. The dependent variable in each model was whether participants chose the more risky project A or the less risky Project B.

The results reveal that the scenario 1 model is not significant with a Chi-square statistic of 6.61 being recorded. This model predicts $70.1 \%$ of the classifications correctly and the Nagerlkerke $\mathrm{R}^{2}$ is .117 . While none of the factors were found to be associated with the project selection decision at a 5\% significance level, the level of the maximum bonus available was the most significant factor $(\mathrm{p}=.08)$. An analysis of the mean responses in relation to this factor reveals that participants who chose Project A (the more risky project) considered the maximum bonus available to a greater extent than participants who chose the less risky project (Project B). 
The Australasian Accounting Business \& Finance Journal, December, 2008.

Baird, Perera \& Meng: Managers' Propensity to Take Risk in Project Selection Decisions.

Vol. 2, No.4.

Page 63.

The scenario 2 model is significant at the .05 level. This model predicts $75.6 \%$ of the classifications correctly and the Nagerlkerke $\mathrm{R}^{2}$ is .220 . The level of the maximum bonus available was the only factor found to be associated with the project selection decision. Once again participants who chose the more risky project (Project A) considered the maximum bonus available to a greater extent when making their decision than participants who chose the less risky project (Project B).

Finally, the scenario 3 model is significant at the .01 level. This model predicts $75.5 \%$ of the classifications correctly and the Nagerlkerke $\mathrm{R}^{2}$ is .345 . While the level of the maximum bonus available was again found to be associated with the project selection decision, the probability that each project generates a loss was also associated with the project selection decision. Specifically, it was found that participants who chose the less risky project (Project B) considered this factor to a greater extent when making their decision than those who chose the more risky Project A. While the probability of a loss was less for Project B (0.1) than Project A $(0.3)$ in all three scenarios, the fact that the magnitude of the potential loss in scenario 3 (up to $20 \%$ ) was higher may explain why this factor was considered at this highest payoff level. Furthermore, the fact that this factor was considered to be important even though respondents could not generate a loss indicates that the respondents undertook their role seriously and considered the company's interests when making their project selection decisions.

The results of the logistic regression analysis in combination with the Chi-square results provide an interesting insight into the factors that influence project selection decisions. Firstly, as revealed in both the Chi-square and logistic regression results participants were found to be more risk averse as the payoff magnitude increased. In analysing the factors that affect project selection decisions, the level of maximum bonus available was the only factor that was associated with the selection of projects in each scenario with participants that considered the maximum bonus to a greater extent more likely to choose the more risky Project A.

However, while the results suggested that the availability of higher bonuses (in scenarios 2 and 3) would result in participants choosing the more risky project (Project A), the overall proportion of respondents choosing this project was lower in scenario 2 than in scenario 1 even though the payoff magnitude was higher. Similarly, the proportion of respondents choosing the more risky project was lower in scenario 3 than was the case in scenario 2 despite the fact that the payoff magnitude was higher. Such findings imply that while the level of maximum bonus available may have had an influence on participants who chose the more risky Project A, respondents placed less emphasis on the maximum bonus in making their decision as the level of payoff magnitude (maximum bonus available) increased.

An alternative explanation of participants' project selection decisions is provided by the scenario 3 (the highest payoff magnitude) logistic regression results which reveal that consideration of the probability of making a loss was significantly associated with the decision to choose the less risky project (Project B). As we are aware that the proportion of respondents that chose the less risky project increased as the payoff magnitude increased it appears that the probability of making a loss is the dominant factor in influencing project selection decisions at this highest payoff magnitude level. In particular, this factor can be used to explain the declining propensity to take risk as the payoff magnitude increases, with the association of this factor with the project selection decision becoming more significant as the payoff magnitude increased 
The Australasian Accounting Business \& Finance Journal, December, 2008.

Baird, Perera \& Meng: Managers' Propensity to Take Risk in Project Selection Decisions.

Vol. 2, No.4.

Page 64.

across the three scenarios. Such findings reveal that as the payoff magnitude increases participants become more concerned with the probability that projects will generate a loss thereby preventing them from receiving any bonus. Hence, it appears that as the payoff magnitude increases participants become more risk averse, choosing the less risky project which provides them with a higher likelihood of receiving some bonus as opposed to the riskier project which has a higher probability of loss and therefore a higher probability that no bonus will be received.

\section{DISCUSSION}

This study provides interesting insights into the impact of payoff magnitude on the propensity to take risk when making project selection decisions. Bonner and Sprinkle (2002) suggested that individuals would become either more risk neutral and select riskier projects in anticipation of receiving better expected returns, or alternatively more risk averse and select projects with more secure but less returns. The results of this study indicate that individuals become more risk averse as the payoff magnitude increases. Specifically, when the maximum bonus level increased, the proportion of participants who selected the higher-risk project decreased, indicating that individuals become more conservative when potentially higher incentive payments are on offer.

The findings of this study are inconsistent with standard economic theory which maintains that absolute risk aversion will be constant or decreasing (Holt and Laury 2002). Such findings are however, consistent with the empirical findings of Binswanger (1980) and Kachelmeier and Shehata (1992) and partially consistent with those of Holt and Laury (2002). In particular, they reflect the findings of Holt and Laury (2002) in a real setting but are inconsistent with their hypothetical setting results where payoff magnitude had no effect on the propensity to take risk. Holt and Laury (2002: 1650) maintain that 'behaviour is a little more erratic with hypothetical payoffs' with individuals more likely to take risks. While this may be the case, the fact that the results reveal that individuals became more risk averse as payoff magnitude increased suggests that these results may be exacerbated in a real setting.

Each of these studies were conducted in experimental settings and involved contrived gambles and a large number of repetitive problems which affected the current wealth of individuals. The current study differed from these studies firstly by providing a different decision making context. Specifically, the current study evaluates the effect of payoff magnitude on the respondents' propensity to take risk in a project selection decision. Hence, while these previous studies have involved a lottery choice setting, the current study created a real life scenario in which respondents were placed in the role of a general manager given the responsibility to make the project selection decision. Accordingly, while the results of the current study are similar to previous studies the findings allow their conclusions to be generalised to a different decision making context.

The findings also provide an important insight into the factors that influence the propensity to take risk. Specifically, it was revealed that risk averse managers consider the probability that each project generates a loss to a greater extent when selecting projects, while risk takers consider the level of the maximum bonus available and the level of weighted average expected bonus to a greater extent. These findings provide an important insight into how managers make project selection decisions and will assist management in attempting to achieve desired behaviour in respect to project selection decisions. 
The analysis of the factors that affected the selection of projects across the three scenarios indicates that while the maximum bonus available was associated with greater risk taking by individuals, as the maximum level of bonus available increased individuals became increasingly concerned with the probability of a loss occurring and hence, no bonus being received. Consequently, given the proportion of risk takers declined as the payoff magnitude increased, the results imply that individuals become more concerned with receiving some bonus as the payoff magnitude increases and less concerned with taking a risk in pursuit of the maximum available bonus. These results are consistent with Kahneman \& Tversky's (1992) prospect theory.

Hence, the results of this study indicate that the increase in payoff magnitude did not provide high enough motivation for participants to choose the riskier project with the propensity to take risk clearly declining as the payoff magnitude increased across the three scenarios. These findings may be attributed to participants choosing the lower-risk project even though it has lower returns (and hence bonuses) associated with it in order to minimise challenges and receive some type of bonus with more certainty. Alternatively, it can be argued that participants are more reluctant to select higher-risk projects due to the greater possibility of project failure, which could subsequently impact on them immediately through no bonuses being received. Such reluctance could also be due to the implications of project failures on the profitability and viability of the company in the long term.

\section{Limitations of the study and future research}

The participants of this study were not drawn from the population of ultimate interest. The population of interest is managers working in commercial companies who are responsible for project selection and capital budgeting decisions, and it is likely that there are differences in the knowledge, industry experience, and private interest between managers and university students. Therefore, the inability to do random sampling from the population is likely to limit the external validity of the current study.

The current study adopts a simplified experimental design, which denied participants the opportunity to exert effort to analyse information and influence return probabilities. In reality the return generated by a project is not like gambling (i.e. purely about probabilities) but can be influenced by the actions of managers. Hence, if a manager correctly identified a potential risk area for a higher-risk project and effectively addressed it, the probability of the project generating positive returns could increase, which in turn could also increase the likelihood that the managers would select that project.

Future research could replicate this study by using managers as participants in the experiment. Post experimental interviews could be conducted to complement the experiment in order to explore more information from the managers, e.g. the considerations behind their project decisions and their attitudes towards risk-taking. The use of such a procedure would improve the external validity of the current study.

Future research could also adopt a more sophisticated experiment design which better replicates reality. Further research could better utilise the learning effect in the context of a multiperiod investment project selection setting, encouraging participants to exert effort to analyse information and to utilise the experience gained from prior trials. 
The Australasian Accounting Business \& Finance Journal, December, 2008.

Baird, Perera \& Meng: Managers' Propensity to Take Risk in Project Selection Decisions.

Vol. 2, No.4.

Page 66.

\section{APPENDICES}

\section{APPENDIX A: Experiment Decision Scenarios}

\section{Scenarios 1-3}

Assume that you are the general manager of XYZ Ltd and you have sole responsibility for choosing between the following two projects. Both projects are expected to involve the same degree of difficulty. Your bonus at the end of the year will be equal to the rate of return generated by the chosen project. For example, if the project generates a return of $10 \%$ you will receive a bonus equal to $10 \%$ of your annual salary; if the project generates a loss you will still receive your normal pay and no penalty will be imposed. Both projects have a weighted average expected return of $4.2 \%(6.6 \%$ in scenario 2 and $8.7 \%$ in scenario 3$)$, this is calculated by the summation of each probability multiplies by respective expected return $\left(\sum\right.$ (Probability $\times$ Expected return $\left.)\right)$.

\section{Project A}

\begin{tabular}{|l|l|l|l|}
\hline Probability & $\begin{array}{l}\text { Return Outcomes } \\
\text { Scenario 1 }\end{array}$ & $\begin{array}{l}\text { Return Outcomes } \\
\text { Scenario 2 }\end{array}$ & $\begin{array}{l}\text { Return Outcomes } \\
\text { Scenario 3 }\end{array}$ \\
\hline 0.10 & $-8 \%$ & $-12 \%$ & $-20 \%$ \\
\hline 0.20 & $-4 \%$ & $-8 \%$ & $-10 \%$ \\
\hline 0.10 & $0 \%$ & $0 \%$ & $0 \%$ \\
\hline 0.30 & $7 \%$ & $11 \%$ & $14 \%$ \\
\hline 0.20 & $11 \%$ & $18 \%$ & $25 \%$ \\
\hline 0.10 & $15 \%$ & $25 \%$ & $35 \%$ \\
\hline
\end{tabular}

\section{Project B}

\begin{tabular}{|l|l|l|l|}
\hline Probability & $\begin{array}{l}\text { Return Outcomes } \\
\text { Scenario 1 }\end{array}$ & $\begin{array}{l}\text { Return Outcomes } \\
\text { Scenario 2 }\end{array}$ & $\begin{array}{l}\text { Return Outcomes } \\
\text { Scenario 3 }\end{array}$ \\
\hline 0.10 & $-4 \%$ & $-8 \%$ & $-10 \%$ \\
\hline 0.20 & $0 \%$ & $0 \%$ & $0 \%$ \\
\hline 0.20 & $4 \%$ & $8 \%$ & $10 \%$ \\
\hline 0.20 & $6 \%$ & $10 \%$ & $13 \%$ \\
\hline 0.20 & $8 \%$ & $12 \%$ & $16 \%$ \\
\hline 0.10 & $10 \%$ & $14 \%$ & $19 \%$ \\
\hline
\end{tabular}

Which project would you choose? 
The Australasian Accounting Business \& Finance Journal, December, 2008.

Baird, Perera \& Meng: Managers' Propensity to Take Risk in Project Selection Decisions.

Vol. 2, No.4.

Page 67.

\section{APPENDIX B: $\quad$ Post Experiment Questionnaire}

1. Which of the two projects do you perceive to involve higher risk? Project $\mathrm{A} \square \quad$ Project B

2. Which of the two projects is likely to generate a higher expectedbonus? Project A $\square$ Project B

3. Please indicate the extent to which each of the following factors were considered in choosing between the two projects.

$\begin{array}{ll}\text { Not at } & \text { To a great } \\ \text { All } & \text { Extent }\end{array}$

The probability that each project generates a loss:

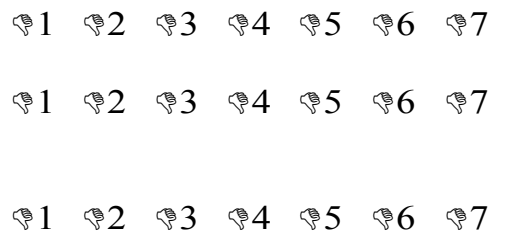

The probability that each project generates a positive return (getting bonus):

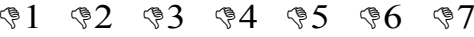

The distribution of positive returns for each project:

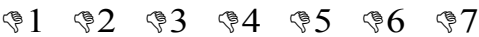

The level of the maximum bonus available:

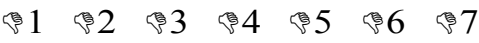

The level of weighted average expected bonus:

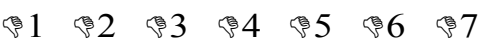


The Australasian Accounting Business \& Finance Journal, December, 2008.

Baird, Perera \& Meng: Managers’ Propensity to Take Risk in Project Selection Decisions.

Vol. 2, No.4.

Page 68.

\section{REFERENCES}

Aggarwal, R. K., and A. A. Samwick, 1999, “The Other Side of the Trade-off: The Impact of Risk on Executive Compensation", Journal of Political Economy 107: 65-105. https://doi.org/10.1086/250051

Amihud, Y., and B. Lev, 1981, "Risk Reduction as a Managerial Motive for Conglomerate Mergers", Bell Journal of Economics 12: 605-617. https://doi.org/10.2307/3003575

Atkinson, A. A., R. S. Kaplan, and S. M. Young, 2003, Management accounting, $4^{\text {th }}$ ed., Upper Saddle River, NJ: Prentice-Hall.

Baiman, S., 1990, “Agency Research in Managerial Accounting: A Second Look”, Accounting, Organisations and Society 15: 341-371. https://doi.org/10.1016/0361-3682(90)90023-N

Baucells, M., and C. Rata, 2006, “A Survey Study of Factors Influencing Risk-taking Behaviour in Real-world Decisions Under Uncertainty”, Decision Analysis 3(3): 163-176. https://doi.org/10.1287/deca.1060.0075

Binswanger, H.P., 1980, “Attitudes Towards Risk: Experimental Measurement in Rural India”, American Journal of Agricultural Economics 62 (3): 395-407. https://doi.org/10.2307/1240194

Bonner, S.E., and G. B. Sprinkle, 2002, "The Effects of Monetary Incentives on Effort and Task Performance: Theories, Evidence, and a Framework for Research", Accounting, Organisations and Society 27: 303-345. https://doi.org/10.1016/S0361-3682(01)00052-6

Booth, P., and A. Schulz, 2004, “The Impact of an Ethical Environment on Managers', Project Evaluation Judgements Under Agency Problem Conditions", Accounting, Organizations and Society 29: 473-488. https://doi.org/10.1016/S0361-3682(03)00012-6

Christian,C., and S. Gupta, 1994, "The Relation Between the Use of Tax Preparers' and Taxpayers' Position”, Journal of the American Taxation Association 16: 72-93.

Cohen, J. R., and G.M. Trompeter, 1998, “An Examination of Factors Affecting Audit Practice”, Contemporary Accounting Research 15: 481-504. https://doi.org/10.1111/j.1911-3846.1998.tb00568.x

Eisenhardt, K. M., 1985, “Control: Organizational and Economic Approaches”, Management Science February: 134149. https://doi.org/10.1287/mnsc.31.2.134

Gamble, J.E., 2000, "Management commitment to innovation and ESOP stock concentration”, Journal of Business Venturing 15: 433-447. https://doi.org/10.1016/S0883-9026(99)00037-3

Garen, J.E., 1994, "Executive Compensation and Principal-agent Theory", Journal of Gamble, J.E., 2000, "Management Commitment to Innovation and ESOP Stock Concentration", Journal of Business Venturing 15: 433-447. https://doi.org/10.1016/S0883-9026(99)00037-3

Hannan, R.L., 2005, “The Combined Effect of Wages and Firm Profit on Employee Effort", The Accounting Review 80: 167-188. https://doi.org/10.2308/accr.2005.80.1.167

Harrell, A., and P. Harrison, 1994, “An Incentive to Shirk, Privately Held Information and Managers’ Project Evaluation Decisions", Accounting, Organizations and Society 19: 569-577. https://doi.org/10.1016/0361-3682(94)90024-8

Harrison, P., and A. Harrell, 1993, "Impact of 'Adverse Selection' on Managers' Project Evaluation Decisions", Academy of Management Journal 36: 635-643. https://doi.org/10.5465/256596

Harrison, P., C. W. Chow, A. Wu, and A. Harrell, 1999, “A Cross-Cultural Investigation of Manager's Project Evaluation Decisions", Behavioral Research in Accounting 11: 144-160.

Haugen, R.A., 2001, Modern Investment Theory, $5^{\text {th }}$ ed., NJ: Prentice-Hall. 


\begin{tabular}{|l|l|}
\hline The Australasian Accounting Business \& Finance Journal, December, 2008. \\
Baird, Perera \& Meng: Managers' Propensity to Take Risk in Project Selection Decisions. \\
Vol. 2, No.4.
\end{tabular}

Holt, C.A., and S.K. Laury, 2002, "Risk Aversion and Incentive Effects", American Economic Review 92(5): 16441655. https://doi.org/10.1257/000282802762024700

Horngren, C.T., G. Foster, and S. M. Datar, 2005, Cost Accounting: A Managerial Emphasis, $12^{\text {th }}$ ed., Upper Saddle River, NJ: Prentice-Hall.

Jeitschko, T.D., and S. D. Jeung, 2005, “Incentives for Risk-taking in Banking - A Unified Approach”, Journal of Banking and Finance 29: 759-777. https://doi.org/10.1016/S0378-4266(04)00057-3

Jia, J., 1995, "Measures of Risk and Risk-Value Theory", Unpublished PhD Dissertation, University of Texas at Austin, TX.

Jia, J., J. S. Dyer., and J. C. Butler, 1999, “Measures of Perceived Risk”, Management Science 45: 519-532.

Kachelmeier, S.J., and M. Shehata, 1992, "Examining Risk Preferences Under High Monetary Incentives: Experimental Evidence From the People's Republic of China", American Economic Review 82(5): 11201141. https://doi.org/10.1287/mnsc.45.4.519

Kahneman, D., and A. Tversky, 1979, "Prospect Theory: An Analysis of Decision Under Risk", Econometria 47: 263-292. https://doi.org/10.2307/1914185

Lee, S.W., 2002, "Insider Ownership and Risk-taking Behaviour at Bank Holding Companies", Journal of Business Finance \& Accounting 29: 989-1005. https://doi.org/10.1111/1468-5957.00458

Lipe,M., 1993, "Analyzing the Variance Investigation Decision: The Effects of Outcomes, Mental Accounting, and Framing", The Accounting Review 68: 748-64.

March, J.G., and Z. Shapira, 1987, "Managerial Perspectives on Risk and Risk Taking", Management Science 33(11): 1404-1418. https://doi.org/10.1287/mnsc.33.11.1404

Moreno, K., T. Kida, and J. F. Smith, 2002, “The Impact of Affective Reactions on Risky Decision Making in Accounting Contexts", Journal of Accounting Research 12: 1331-1349. https://doi.org/10.1111/1475-679X.t01-1-00056

Rutledge, R.W., and K. E. Karim, 1999, "The Influence of Self-interest and Ethical Considerations on Managers' Evaluation Judgements", Accounting, Organizations and Society 24: 173-184. https://doi.org/10.1016/S0361-3682(98)00027-0

Simnett, R., 1996, "The Effect of Information Selection, Information Processing and Task Complexity on Predictive Accuracy of Auditors", Accounting, Organisations and Society 21: 699-719. https://doi.org/10.1016/0361-3682(96)00006-2

Slovic, P., 1967, "The Relative Influence of Probabilities and Payoff Upon Perceived Risk of a Gamble", Psychonomic Science 9: 223-224. https://doi.org/10.1037/e301272005-001

Sullivan, K., and T. Kida, 1995, “The Effect of Multiple Reference Points and Prior Gains and Losses on Managers' Risky Decision Making", Organizational Behaviour and Human Decision Processes 64: 76-83. https://doi.org/10.1006/obhd.1995.1091

Tabachnick, B.G., and L. S. Fidell, 2001, Using multivariate statistics, $4^{\text {th }}$ ed., Allyn and Bacon, Boston.

Vroom, V., 1964, Work and motivation, New York, NY: John Wiley.

Zimmerman, J.L., 2000, Accounting for decision making and control, $3^{\text {rd }}$ ed., Boston, MA: Irwin/McGraw-Hill. 